\title{
FINANCE GAME: UM JOGO DE APOIO À EDUCAÇÃO FINANCEIRA
}

\author{
Rodrigo de Castro Teixeira Junior - Ifes, rodrigo_c_t@hotmail.com \\ Arthur Teixeira Traspadini - Ifes, arthurtraspadini@hotmail.com \\ Vinicius Alves Sant'ana - Ifes, vinicin46@hotmail.com \\ Danilo Batista Nascimento - Ifes, dbnascimentto@gmail.com \\ Vanessa Battestin Nunes - Ifes, vanessa@ifes.edu.br \\ Isaura Alcina Martins Nobre - Ifes, isaura@ifes.edu.br
}

\begin{abstract}
Resumo. Vivemos hoje um momento em que se explora cada vez mais o consumismo excessivo e em que muitas pessoas gastam mais do que ganham, vivendo em um constante endividamento. A educação financeira se mostra extremamente necessária desde a infância, para que decisões sensatas e planejadas possam ser tomadas. Diante desse cenário, este artigo apresenta um jogo educativo de apoio à educação financeira, que objetiva apoiar a tomada de decisões visando o equilíbrio financeiro e a qualidade de vida. Para seu desenvolvimento foi utilizada a metodologia XisOA. O jogo foi bem avaliado por uma especialista da área de educação, que também apontou aspectos a serem melhorados, e, da mesma forma, foi bem avaliado na opinião de algumas crianças que o jogaram.
\end{abstract}

Palavras-chaves: Jogo educativo. Educação Financeira. Tecnologia Educacional.

\section{FINANCE GAME: A SUPPORT GAME FINANCIAL EDUCATION}

Abstract. Today we live in a time that explores increasingly excessive consumerism and that many people spend more than they earn, living in a constant debt. Financial education shows extremely necessary since childhood, so that sound decisions can be taken and planned. In this scenario, this article presents an educational game to support financial education, which aims to support decision-making aimed at financial stability and quality of life. The methodology used for its development was XisOA. The game was well evaluated by a expert in the area of education, which also pointed out aspects to be improved, and, likewise, was well rated in the opinion of some children who played.

Keywords: Educational game. Financial Education. Educational technology.

\section{INTRODUÇÃO}

A educação financeira tem ganhado destaque mundial por apresentar um grande papel na formação das pessoas, promovendo equilíbrio, conforto e qualidade de vida. Porém, ainda se apresenta tímida no Brasil, tanto por parte das instituições de ensino, como pelas famílias. As contribuições proporcionadas por uma boa gestão das finanças extrapolam o âmbito financeiro, pois as pessoas que as mantém em ordem tendem a tomar boas decisões e enfrentar melhor suas adversidades. E isso ajuda não só na vida financeira, mas também 
em aspectos familiares, sociais e profissionais, impactando diretamente em sua qualidade de vida.

O ideal é que a educação financeira seja inserida desde cedo nas vidas das pessoas, visando torná-las mais responsáveis e equilibradas, preparando-as para situações futuras e reduzindo ocorrências adversas, causadas pela má administração.

Atualmente, as tecnologias têm sido uma forte aliada da educação. Quando tratamos do ensino de crianças, essa tecnologia se torna ainda mais útil, principalmente quando envolvem jogos ou softwares educativos. Segundo Vieira (2009), software educativo consiste em um ambiente interativo que leva o aprendiz a construir seu próprio conhecimento, permitindo a ele investigar, fazer levantamento de hipóteses e testá-las, de modo a aperfeiçoar suas ideias iniciais.

Um segmento desses softwares é classificado como Jogos. Com o crescimento das tecnologias mobile, os jogos se consolidaram como o tipo mais comuns entre a maioria população. Todo seu atrativo gráfico, bem como os diversos desafios, tem despertado, especialmente, a atenção das crianças. Nesse segmento, “[...] os estudantes ficam mais motivados a usar a inteligência, pois querem jogar bem; sendo assim, esforçam-se para superar obstáculos, tanto cognitivos quanto emocionais. Estando mais motivadas durante o jogo, ficam também mais ativas mentalmente" (IDE, 1996, p.90).

$\mathrm{Na}$ busca por jogos educativos voltados para educação financeira, foram encontrados inicialmente alguns sites de bancos. Porém, apesar de serem chamados de jogos, são, na verdade, sites informativos, em que são mostradas algumas informações úteis sobre finanças, mas não permitem a interação. Além destes, outras duas ferramentas que apoiam a educação financeira foram encontradas. O primeiro é o site "Turma da Bolsa" (www.turmadabolsa.com.br), focado em exibir os conteúdos sobre como economizar e a forma correta de gastar suas economias. Com o foco nas crianças, traz vídeos animados, mas se limita apenas a esta mídia, em um total de 32 vídeos em nível iniciante. Também não possui interação e os conhecimentos do jogador não são testados. O outro site é o "Bate Bola Financeiro" (www.batebolafinanceiro.com.br), do Banco do Brasil. Ele tem nível mais avançado e permite que se coloquem os conhecimentos em prática através de um quiz interativo. Existe uma área onde se pode estudar sobre os conteúdos das perguntas que serão feitas e, durante uma partida de futebol, o jogador precisa responder corretamente as perguntas aleatórias para efetuar gols e ganhar do time adversário. Apesar de permitir testar seus conhecimentos teóricos, não permite a tomada de decisão em situações reais que não as do jogo. Não consideramos aqui o "Desafio SEBRAE", que apesar de bem interessante no contexto da educação financeira, é voltado apenas a universitários que participam do desafio e não ao público em geral, especialmente crianças, foco deste trabalho.

Sendo assim, os jogos encontrados, apesar de permitirem acesso a informações sobre gestão financeira, não permitem que o jogador ponha em prática os conteúdos abordados, como controlar gastos, utilizar seus ganhos ou desenvolver seu próprio negócio (a não ser um, por meio de um quiz) e não possibilitam a tomada de decisão.

Diante desse cenário, o presente trabalho tem como objetivo propor um jogo educativo tendo como tema a Educação Financeira. Nesse jogo, a criança (por meio da simulação do papel de um adulto) irá não somente administrar suas finanças, mas deverá buscar um equilíbrio entre sua vida financeira e outras atividades cotidianas, visando um aumento da sua qualidade de vida. O jogo busca mostrar, por meio de uma abordagem simplificada, algumas diferentes situações que podem ocorrer e que necessitem de análises e tomadas de decisões. 


\section{EDUCAÇÃO FINANCEIRA}

O termo educação financeira, segundo Jacob et al. apud Lucci et al. (2006, p. 04), aplica-se às atividades relacionadas ao dinheiro na vida cotidiana das pessoas, como controle do orçamento, utilização de cartões de crédito, cheques e decisão de investimento.

Já segundo Hill (2009), a educação financeira pode ser definida como a habilidade que os indivíduos apresentam de fazer escolhas adequadas ao administrar suas finanças pessoais durante o ciclo de sua vida. Segundo Braunstein e Welch (2002), além do benefício pessoal, a educação financeira favorece o melhor desenvolvimento do mercado financeiro, uma vez que o estimula a oferecer melhores serviços:

[...] participantes informados ajudam a criar um mercado mais competitivo e eficiente. Consumidores conscientes demandam por produtos condizentes com suas necessidades financeiras de curto e longo prazo, exigindo que os provedores financeiros criem produtos com características que melhor correspondam a essas demandas (BRAUNSTEIN E WELCH, 2002, p. 445).

Os altos índices de inadimplência e endividamento, bem como o consumismo excessivo e, como consequência, a baixa de poupança de um país, podem ser indicativos de carência de educação financeira dos indivíduos (GRUSSNER, 2007, p.19). Segundo Vieira (2004), o comportamento de um indivíduo é amplamente determinado pela maneira como ele pensa e processa a informação adquirida ao longo de sua vida.

Diante desse cenário, diversas correntes científicas, como a Psicologia Econômica, o Marketing, as Finanças Comportamentais, a Teoria dos Jogos, vêm estudando o comportamento dos consumidores frente às atitudes de comprar, vender, consumir, poupar e se endividar. Porém, muitas vezes esses estudos são realizados não com a intenção de conscientização financeira, mas como maneira de estímulo ao consumismo. Para reverter esse processo, ou seja, para que as crianças obtenham os conhecimentos necessários relativos à educação financeira, é fundamental que exista uma ação consciente e constante para que saiam de uma posição passiva, como espectador da sua própria vida, e passem a ter papel ativo, tomando decisões conscientes. Pensando nisso, umas das metas da disciplina de matemática na LDB (Lei de Diretrizes e Bases da educação) é justamente a educação financeira.

Dentro desse contexto, os jogos e simuladores educacionais podem oferecer uma potencialidade metodológica bastante significativa, pois conseguem aliar os benefícios do avanço tecnológico às vivências, mesmo em um ambiente virtual, que são necessárias ao processo de aprender (MOREIRA, 2011).

\section{JOGOS EDUCATIVOS}

Os jogos educacionais são ferramentas úteis para a criança testar conhecimentos aprendidos sobre um determinado assunto, assim como para aprender algo novo, dependendo de seus objetivos. A vantagem é a possibilidade de unir, em uma única ferramenta, varias áreas de conhecimento e de ser mais fácil fazer com que a criança se interesse por conteúdos que muitas vezes são considerados "chatos" se ensinados de forma tradicional.

Os jogos educativos diferem dos tradicionais no que tange o objetivo principal do aplicativo, que é fazer com que o usuário aprenda algo ou reforce algum conhecimento aprendido. Já os jogos tradicionais tem, na grande maioria das vezes, um foco quase que 
exclusivo no entretenimento do usuário, se preocupando pouco ou nada com passar uma mensagem ou contribuir de forma construtiva com o seu jogador.

Sobre o uso de jogos no processo de aprendizagem, segundo Valente (1993, p.4) “A pedagogia por trás desta abordagem é a exploração autodirigida ao invés da instrução explícita e direta". O uso de jogos faz com que a criança busque aprender, estabeleça as conexões e coloque em prática o que aprendeu no decorrer do jogo, o que torna o processo mais interativo. Muitas vezes, é necessário "ensinar" ao aluno não um conteúdo novo, mas sim a aplicar os conteúdos já aprendidos levando em consideração determinado contexto, ou seja, é necessário que o aluno saiba como tomar uma decisão e aplicar seus conhecimentos.

Segundo Johnsson (2002, p.3), a Tomada de Decisão é “[...] uma ação, reativa ou pró-ativa, baseada na aquisição e compreensão de novos conhecimentos". Dessa forma, ensinar o processo de tomada de decisão é uma tarefa não trivial, pois envolve sempre situações especificas.

Comumente, para auxiliar nesse processo de aprendizagem, são utilizados "Estudos de Caso", onde dada uma situação avaliam-se as decisões tomadas, suas consequências e possíveis alternativas que poderiam ter sido tomadas. Para auxiliar nessa atividade, existe a possibilidade de se empregar jogos capazes de simular determinados cenários e fazer com que o jogador tenha que analisar as situações para tomar uma decisão. Este é o caso do jogo do presente trabalho.

\section{METODOLOGIA E PROCESSO DE CONSTRUÇÃO}

Inicialmente, foi realizada uma revisão de literatura sobre jogos educativos e educação financeira e uma busca por trabalhos correlatos. Com base nos resultados encontrados, foram definidas as principais diretrizes do jogo.

Para o desenvolvimento do jogo, foi utilizada a metodologia XisOA (NASCIMENTO e NOBRE, 2008), que se trata de um processo para desenvolvimento de Objetos de Aprendizagem (OAs). Tal metodologia se baseia em conceitos do processo ágil de desenvolvimento de software - Extreme Programming - XP, que possui um conjunto das melhores práticas (modular, iterativa, incremental, ligada ao tempo, parcimoniosa, adaptável, convergente, colaborativa e complementar) para o processo desenvolvimento de software.

Foram elaborados mapas conceituais envolvendo as principais definiçõos utilizadas no jogo. Após isso, foram especificados os cenários do jogo, definindo as interações, restrições e requisitos. Em seguida, iniciou-se o processo de construção, o qual foi realizado utilizando-se a linguagem JavalWEB, HTML 5, JSF e JavaScript. Ao final, foram realizados testes caixa branca e preta, além de ser exposto para testes por crianças. Adicionalmente, o jogo foi analisado por uma especialista da área educativa para validar se o jogo atingiria os objetivos esperados e apontar sugestões de melhoria.

\section{O JOGO FINANCE GAME}

O jogo Finance Game foi desenvolvido a fim de envolver as crianças, já alfabetizadas, em um cenário parecido com o real, em que são expostas tarefas administrativas e financeiras visando à tomada de decisões, buscando um equilíbrio em suas escolhas. 
O jogo ocorre em uma Cidade e simula a vida de um trabalhador, abordando as áreas profissionais, pessoais, educacionais e de sua saúde. $\mathrm{O}$ jogador deve administrar sua casa e sua Lanchonete, sendo necessário pagar contas, comprar alimentos, roupas e outros itens, sempre buscando manter um equilíbrio em suas atividades, seus ganhos e seus gastos. Ou seja, além de lidar com suas finanças, com os ganhos oriundos do seu trabalho e buscando economizar e ser sensato em suas compras, o jogador deve também se divertir, buscar formação, uma vida confortável, mas deve, por outro lado, evitar realizar atividades de maneira excessiva ou, ao invés de ganhar, poderá perder em qualidade de vida.

Assim, todas as decisões foram parametrizadas em um atributo denominado Qualidade de Vida, o qual reflete o desempenho do jogador. Esse parâmetro varia de zero a cem, sendo que quanto menor esse valor, pior é o desempenho e, se chegar a zero, o jogo encerra (game over).

O layout do jogo, apresentado na Figura 1, é divido da seguinte maneira: na lateral esquerda é exibida a foto (ou avatar do jogador) e as informações gerais: qualidade de vida, dinheiro e turno; na lateral direita são apresentadas mensagens instrutivas (dicas e alertas), as quais buscam alertar e auxiliar o jogador em suas decisões, apresentadas em três cores de acordo com a prioridade de impacto da ação necessária: vermelha (alta), amarela (média) e verde (baixa); no centro ocorre o jogo em si, sendo expostos os diversos cenários.

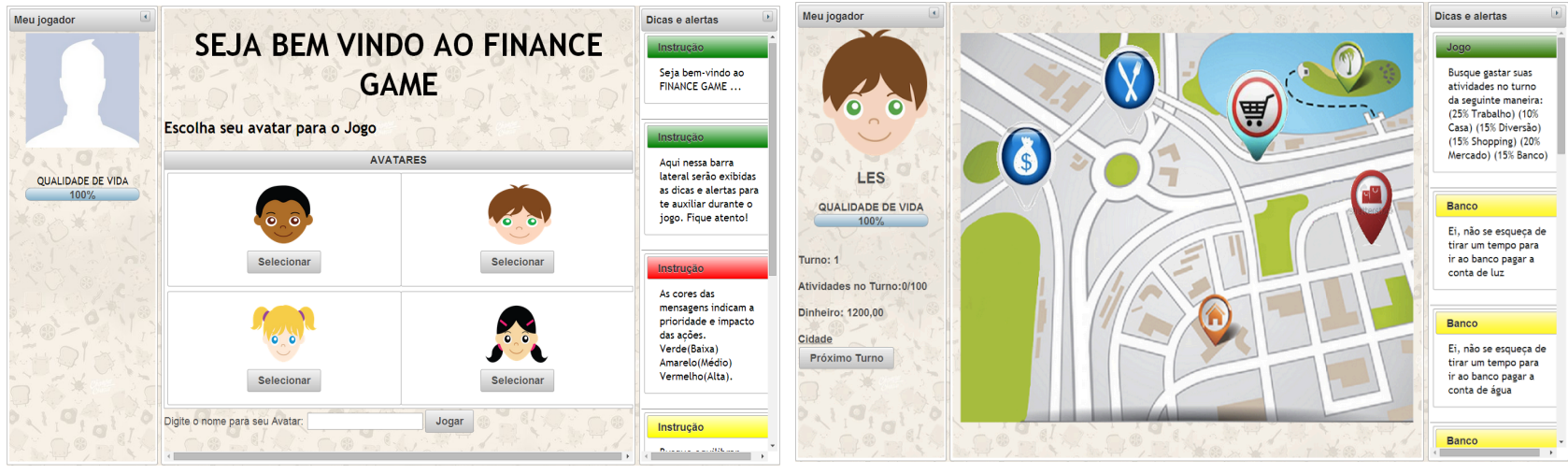

Figura 1 - Tela Inicial do Finance Game e sua estruturação visual.

A organização temporal do jogo foi abstraída para uma representação em Turnos, eliminando a imposição de tempo para a realização das tarefas e gerenciamento dos afazeres. Essa definição foi realizada para permitir que o jogador tenha o tempo necessário para tomar suas decisões, uma vez que este é o foco do jogo, ao invés de ter a preocupação com o tempo, levando-o a tomar decisões rápidas ou mesmo agindo por impulso, sem refletir. Em cada turno, ele pode realizar um total de cem pontos de atividade, sendo que cada Atividade pode apresentar valores diferentes. As atividades se dividem em: Trabalhar, ir ao Mercado, ir ao Shopping, ir a Praia, ir ao Banco e ir a Casa. A atividade de ir trabalhar é a que mais consome, totalizando 20 pontos, já as outras atividades consomem 5 pontos.

As escolhas de realizar uma nova atividade estão disponíveis na tela da Cidade, que mostra um mapa com as opções de cenários possíveis (segunda tela da Figura 1). Ao clicar em um novo cenário, o jogo se redireciona a página específica do mesmo. Caso o jogador efetive aquela atividade, o número de pontos de atividade é decrementado. 
A primeira tela da Figura 2 apresenta o cenário Mercado, onde o jogador pode comprar itens tanto para o estoque de sua lanchonete quanto para a dispensa de sua casa. Nele são disponibilizados alguns itens iguais, porém com valores unitários diferentes, por exemplo: 10 pães por $\mathrm{R} \$ 5,00$ e 20 pães por $\mathrm{R} \$ 9,00$. O objetivo, neste caso, é levar o jogador a refletir sobre as opções disponíveis para que possa tomar a decisão mais sensata, seja de adquirir mais e pagar menos por unidade (se precisar de maior quantidade) ou, quando for necessária uma pequena quantidade, comprar menos e evitar desperdício. Uma dica quanto à isso é exibida na barra lateral direita. Para um melhor resultado, é necessário que o jogador efetue alguns cálculos simples, referentes as quatro operações básicas, fazendo com que o jogo estimule, também, o raciocínio matemático, diretamente relacionado à educação financeira. A preocupação com o desperdício foi traduzida no jogo pela inserção de validade nos itens. Cada item tem validade de alguns turnos, ou seja, à medida que vão passando os turnos, a validade dos itens comprados é decrescida. $\mathrm{O}$ objetivo aqui é incentivar a reflexão sobre o desperdício e o consumo excessivo. Um cenário similar ao mercado é o Shopping, em que a diferença se dá apenas nos itens, que ao invés de alimentos são roupas, sapatos e itens para casa, como mesa, sofá e televisor.
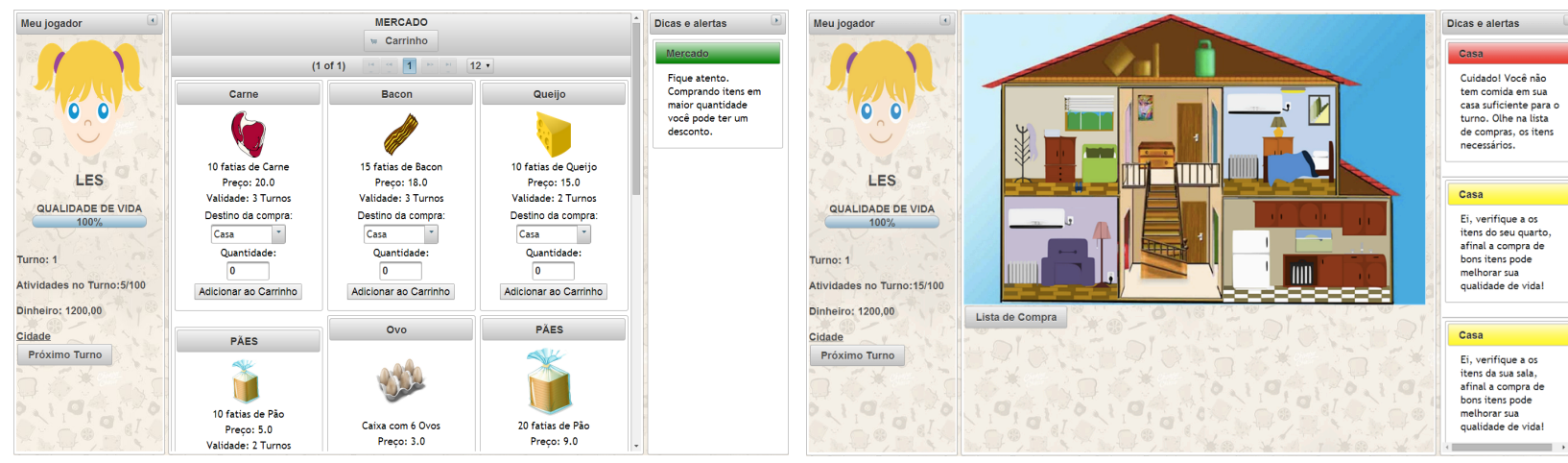

Figura 2 - Cenário do mercado e distribuição dos itens.

No cenário Casa (segunda tela da Figura 2), o jogador visualiza todos os cômodos e pode clicar no que desejar. Ele deve comprar itens e administrar: sua dispensa de alimentos (na cozinha), seu guarda-roupa (no quarto) e seus móveis da sala (sofá, tv etc.). O gerenciamento da dispensa é por meio de uma lista de compras que detém todos itens necessários para se alimentar naquele turno. Caso, ao final do turno, o jogador não apresente o mínimo de alimento necessário, sua qualidade de vida é decrescida em uma unidade a cada item em falta. Caso apresente todos os alimentos necessários, ele ganha 4 pontos em sua qualidade de vida. Já em seu guarda-roupa e sua sala, deve ter no mínimo um modelo de cada item, de modo que a cada falta de um item o jogador terá sua qualidade de vida diminuída em uma unidade. Além disso, a fim de evitar um consumo excessivo, caso adquira mais de 4 tipos de um item, também sofrerá uma penalização de uma unidade em sua qualidade de vida. Se tiver todos os itens dentro de uma quantidade permitida, ele terá sua qualidade de vida aumentada em 4 unidades (ou mais dependendo dos itens adquiridos). O objetivo aqui é incentivar a reflexão sobre como ter uma vida equilibrada, visando atender suas necessidades básicas de alimentação, buscando-se formas de conforto que podem lhe proporcionar maior qualidade de vida, mas ao mesmo tempo evitando-se os desperdícios.

O Banco é onde o jogador pode pagar suas contas (água, luz e telefone). O não pagamento gera, ao final do turno, uma multa de $20 \%$ sob o valor de cada conta que ficou 
pendente, que serão automaticamente descontados de suas finanças. É no banco, também, que o jogador pode adquirir um empréstimo para aliviar sua situação financeira ou efetuar compras (primeira tela da Figura 3). Porém, o jogador pode ter apenas um empréstimo ativo por vez. Ao todo são quatro os valores oferecidos: $\mathrm{R} \$ 100,00, \mathrm{R} \$ 250,00, \mathrm{R} \$ 400,00 \mathrm{e}$ $\mathrm{R} \$ 500,00$, e este valor pode ser dividido em uma a quatro parcelas (que devem ser pagas até o final de cada turno, a partir do turno seguinte ao empréstimo). O banco traz duas ideias bastante importantes: a primeira é a da responsabilidade para pagar as contas em dia e as consequências de não fazer isso (a multa). Muitas vezes, as pessoas se comprometem com compras antes de arcar com seus compromissos financeiros e, quando vão fazer isso, por vezes não possuem a quantia necessária, o que acarreta juros e multas e muitas vezes as levam a ter de recorrer aos empréstimos. A segunda parte importante é buscar conscientizar os jogadores de que um empréstimo pode ser necessário em diversas situações da vida, mas deve ser adquirido com muita cautela.

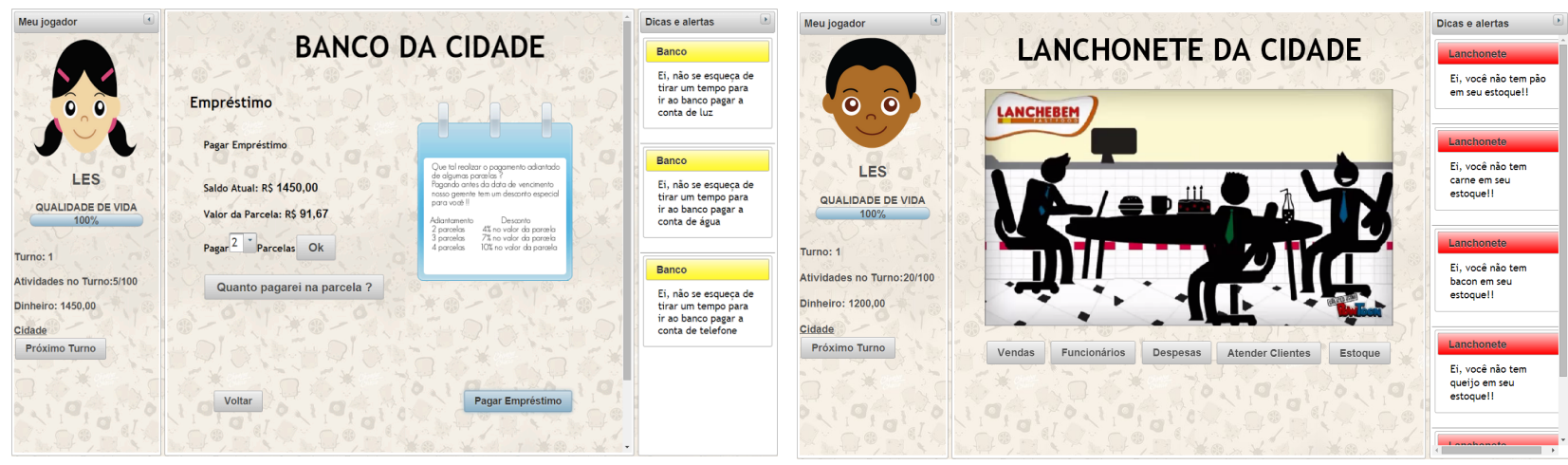

Figura 3. Cenário da lanchonete e as opções de atividades.

A Lanchonete é o local de trabalho do jogador (segunda tela da Figura 3). Esta é única fontes de renda no jogo (fora os empréstimos). $\mathrm{O}$ jogador deve cuidar do seu estoque, indo ao mercado sempre que for preciso adquirir ingredientes que estejam em falta ou quando julgar necessário produzir mais lanches e, consequentemente, estar apto a atender mais clientes, gerando uma renda maior (alertas quanto a isso são exibidos). O jogador também deve cuidar da contratação de funcionários, caso deseje aumentar a capacidade de produção de lanches, neste caso tendo que arcar com o(s) salário(s) e demais impostos relativos ao(s) mesmo(s). O jogador pode ir trabalhar sem ter ingredientes suficientes em estoque para atender o número máximo previsto de clientes para o dia (este número é gerado aleatoriamente dentro de uma faixa [MIN, MÁX], de modo que o jogador não sabe o valor exato). Porém, a cada cliente que o jogador deixar de atender, resultará em um impacto negativo em sua qualidade de vida (a cada 4 clientes não atendidos, a qualidade de vida decresce em um unidade) e também na previsão de clientes que irão ao estabelecimento no turno seguinte (a cada 5 clientes não atendidos o faixa geração aleatória diminui uma unidade). De forma, contrária, se tiver ingredientes para produzir lanches suficientes para o total de clientes, isso aumentará tanto a sua qualidade de vida (aumento de 3 unidades) quanto os clientes esperados para a próxima etapa (aumento de 20 unidades na faixa de geração aleatória). Se, por ventura, exagerar na quantidade, itens podem passar do prazo de validade. Inicialmente, o jogador possui uma estimativa de clientes que irão ao estabelecimento e este número é mostrado em um intervalo entre um mínimo e um máximo. Assim, cabe ao jogador decidir a postura que irá adotar: comprar ingredientes para atender o número mínimo (ou abaixo do) esperado para o dia, ser precavido e comprar 
ingredientes para o total mostrado (ainda que este total possa não ser atingido, pois o número é gerado aleatoriamente dentro do intervalo pré-estabelecido) ou comprar excessivamente. Para melhores resultados, ele deverá efetuar as contas necessárias. Aqui, o objetivo é levar o jogador a refletir sobre as consequências das decisões tomadas como, por exemplo, que um gasto maior de investimento no seu negócio muitas vezes é necessário para gerar mais lucros no futuro, mas que isso também deve ser realizado com cautela e dentro das condições de que dispõe no momento.

De forma geral, o jogo busca tirar o jogador de uma postura passiva e reativa, como muitos infelizmente fazem na vida real, comprando itens desnecessários, desperdiçando, fazendo empréstimos e dívidas, não arcando com suas responsabilidades e não investido corretamente em seu negócio. Visa, assim, fazer o jogador refletir sobre suas ações antes de tomar decisões e vislumbrar as consequências das mesmas. Porém, sempre com a preocupação de mostrar que o mais importante não é apenas arcar com as responsabilidades, ganhar dinheiro e economizar, mas que deve haver um equilíbrio, buscando-se, também, satisfação pessoal e qualidade de vida.

\section{AVALIAÇÃO}

Inicialmente, algumas crianças (entre 12 e 15 anos) foram convidadas a testar o jogo. $\mathrm{O}$ fato de terem ficado um bom tempo jogando por si só já foi positivo, uma vez que crianças desta idade em geral não dedicam muito tempo em algo de que não gostam. Além disso, apontam que os ajudou a realizar contas cotidianas, tomar decisões visando maximizar o ganhos, mas equilibrar com a qualidade de vida. Algumas falas evidenciam isso:

O jogo é legal e ajuda a gente a aprender fazer contas, e diz quanto que a gente deve gastar pra aumentar nossa qualidade de vida. É legal que a gente tem que escolher a quantidade certa de ingredientes para poder atender todos os clientes e ganhar mais dinheiro (menino de 12 anos).

O joguinho é interessante e motivador, porque a gente deve saber comprar, gastar e equilibrar nossas atividades para aumentar a qualidade de vida. Tem imagens legais, e a barra de alertas ajuda muito a gente a decidir e prestar atenção no que está errado (menina de 15 anos).

Os aspectos destacados pelas crianças são bastante relevantes porque evidenciam justamente os objetivos centrais do jogo, ou seja, que a criança aprende a lidar um pouco mais com a gestão financeira, por meio da realização de cálculos diversos, mas sem fazer isso de forma desenfreada, apenas visando o lucro ao máximo ou o consumismo exacerbado e prejudicando outros aspectos de sua vida, mas, ao contrário, buscando um equilíbrio, que visa a uma melhor qualidade de vida. Para tal, as crianças são submetidas a diversos momentos de tomadas de decisão, extremamente importantes no processo de construção de conhecimento e para o desenvolvimento de cidadãos críticos.

Convidamos, ainda, uma especialista da área de educação para avaliar o jogo. Para tal, foi desenvolvido um questionário baseado em (ALBERNAZ, 2008) e (NOBRE et al, 2011), com requisitos de usabilidade e pedagógicos e um espaço para sugestões. A avaliadora é professora, tendo experiência de mais de 20 anos na educação básica e superior. As respostas constam na Tabela 1.

Pode-se verificar que o jogo teve uma boa avaliação, sendo que nenhum item foi marcado como "Não atende". Porém, foram apontoados aspectos que podem ser melhorados, ao marcar alguns itens como "Atende parcialmente", e pelas sugestões de 
melhorias dadas. É válido destacar que maioria delas já foi implementada e outras ficaram para trabalhos futuros.

Tabela 1. Avaliação do jogo por uma especialista da área de Educação.

\begin{tabular}{|c|c|c|c|c|}
\hline REQUISITOS & Atende & $\begin{array}{l}\text { Atende } \\
\text { Parcialme } \\
\text { nte }\end{array}$ & $\begin{array}{l}\text { Não } \\
\text { Atende }\end{array}$ & $\begin{array}{l}\text { Não se } \\
\text { aplica }\end{array}$ \\
\hline \multicolumn{5}{|l|}{ Requisitos de Usabilidade } \\
\hline $\begin{array}{l}\text { 1. A linguagem é adequada ao público alvo definido e ao nível de ensino a que se } \\
\text { refere. }\end{array}$ & $\mathrm{X}$ & & & \\
\hline 2. É atrativo, envolvendo e cativando o aluno em sua utilização. & $\mathrm{X}$ & & & \\
\hline 3. São usadas múltiplas mídias (imagens, animações, vídeos, música etc). & & $\mathrm{X}$ & & \\
\hline $\begin{array}{l}\text { 4. O tema é apresentado de forma lúdica e explora uma metáfora esclarecedora } \\
\text { para o aluno. }\end{array}$ & $\mathrm{X}$ & & & \\
\hline 5. Permite e incentiva a crescente autonomia e o envolvimento do aluno. & $\mathrm{X}$ & & & \\
\hline 6. O aluno consegue interagir com o programa facilmente. & & $\mathrm{X}$ & & \\
\hline 7. Existe interação com outros usuários. & & & & $\mathrm{X}$ \\
\hline 8. Promove a criatividade (podem existem vários caminhos/ respostas/ soluções). & & $\mathrm{X}$ & & \\
\hline $\begin{array}{l}\text { 9. O tempo de cada ação é adequado. Existe a possibilidade de repetição. As } \\
\text { etapas não são exaustivas. }\end{array}$ & $\mathrm{X}$ & & & \\
\hline 10. As regras são coerentes e estão de acordo com o mundo imaginário proposto. & & $\mathrm{X}$ & & \\
\hline 11. O nível de concentração exigido está de acordo com o público do jogo. & $\mathrm{X}$ & & & \\
\hline \multicolumn{5}{|l|}{ Requisitos Pedagógicos } \\
\hline $\begin{array}{l}\text { 12. O conteúdo é coerente e contextualizado com a área e o nível de ensino } \\
\text { propostos. }\end{array}$ & $\mathrm{X}$ & & & \\
\hline $\begin{array}{l}\text { 13. O grau de dificuldade é variável, podendo ser definido pelo aluno ou passando } \\
\text { de níveis de dificuldade menor para maiores, de acordo com os avanços } \\
\text { obtidos. }\end{array}$ & & & & $\mathrm{X}$ \\
\hline 14. Aborda os conteúdos de forma a facilitar o aprendizado. & & $\mathrm{X}$ & & \\
\hline $\begin{array}{l}\text { 15. Oferece feedbacks construtivos, permitindo ao aluno identificar claramente } \\
\text { quando acertou e repensar suas ideias e estratégias quando não forem bem } \\
\text { sucedidas. }\end{array}$ & & $\mathrm{X}$ & & \\
\hline $\begin{array}{l}\text { 16. É dado algum incentivo ou premiação ao se atingir certos marcos, a fim de } \\
\text { motivar o aluno. }\end{array}$ & $\mathrm{X}$ & & & \\
\hline $\begin{array}{l}\text { 17. Faz referência ao universo cotidiano dos alunos, em uma perspectiva de } \\
\text { formação e de cidadania. }\end{array}$ & $\mathrm{X}$ & & & \\
\hline \multicolumn{5}{|c|}{$\begin{array}{l}\text { Consideraçães / Sugestões de Melhorias } \\
\text { - } \\
\text { - } \quad \text { Sobre na tela de instrução logo no inicio colocar o objetivo do jogo } \\
\text { - Os percentuais utilizados como parâmetros para as alterações da qualidade de vida } \\
\text { - Orientar que clicar na cidade corresponde ao botão de voltar } \\
\text { - Colocar texto sobre as imagens na cidade para esclarecer ao que corresponde cada um } \\
\text { Alterar os itens da casa - quarto (roupas e acessórios) / dispensa (cozinha) / ou inserir itens básicos para compra como } \\
\text { cama, guarda-roupa, fogão, geladeira etc. } \\
\text { Orientar as compras - instrução mínima - selecionar produtos e ir para o carrinho e depois clicar em comprar - tipo nao } \\
\text { deixar voltar para cidade sem perguntar se o usuário deseja ou nao confirmar a compra no carrinho - algo assim } \\
\text { - O vermelho some e o amarelo por ser apenas instrução náo some -avisar o usu[ario } \\
\text { - Falterar o formato do carrinho para permitir alterar quantidade e excluir marcando os itens } \\
\text { - Salvar o status do jogo antes de encerrar - botão encerrar } \\
\text { Teria que ser pensado a questão do aprendizado propriamente dito - avaliar junto ao publico-alvo o aprendizado } \\
\text { alcançado. }\end{array}$} \\
\hline
\end{tabular}

\section{CONCLUSÕES}

O presente artigo apresentou o jogo Finance Game que tem como objetivo auxiliar crianças a lidar com a gestão financeira em equilíbrio com outros aspectos que afetem a qualidade de vida.

Esperamos que as ações no jogo, levem o indivíduo a uma tomada de consciência no campo da educação financeira que possa lhe ajudar em toda sua vida. Como dizia Piaget 
(1997), a tomada de consciência permite ao sujeito passar da situação de "ter êxito" em um problema ao de "compreender" porque houve êxito ou fracasso, uma vez que tenta conhecer e modificar seu próprio conhecimento. Além disso, para ele, essa tomada de consciência se trata "[...] muito mais de graus de integração do que de passagens bruscas da inconsciência para à consciência" (p. 203), o que acreditamos ser possível ocorrer ao longo da interação do sujeito com o jogo, especialmente se o uso tiver alguma continuidade.

Como foi exibido, o jogo foi bem avaliado por uma especialista da área de educação e bem aceito por algumas crianças que o testaram. Porém, por ser uma versão inicial, necessita ainda de alguns ajustes e melhorias. Outra ideia futura é disponibilizá-lo para celular e tablet.

\section{REFERÊNCIAS}

ALBERNAZ, Jussara Martins. Jogo Computacional como Desencadeador da Aprendizagem de Matemática nas Séries Iniciais do ensino fundamental: sua avaliação por professores e alunos. Vitória, 2008.

GRUSSNER, Paula Medaglia. Administrando as Finanças Pessoais para criação do Patrimônio. Porto Alegre: UFRGS, 2007. Monografia de graduação.

HILL, N. Quem pensa enriquece. São Paulo: Fundamento Educacional, 2009.

IDE, Sahda Marta. O jogo e o fracasso escolar. In: KISHIMOTO, Tizuko Morchida (Org.). Jogo, brinquedo, brincadeira e a educação. São Paulo: Cortez, 1996.

JOHNSSON, Marcelo Evandro. A importância da utilização de jogos de empresas em programas de capacitação de executivos. Curitiba: Revista Fae Business, 2002.

LUCCI, C.; ZERRENNER, S.; VERRONE, M.; SANTOS, S. A Influência da educação financeira nas decisões de consumo e investimento dos indivíduos. In: IX SEMEAD. Administração no Contexto Internacional. Seminários em Administração FEA-USP, 2006.

MOREIRA, Marcos André Porto. Aplicação de um Método Ativo de Educação para administração Financeira: o caso de um simulador empresarial. Fortaleza: Universidade de Fortaleza - UNIFOR, 2011. Dissertação de mestrado.

NASCIMENTO, E. L.; NOBRE, Isaura A. M. Um Processo de Desenvolvimento de Software baseado em Extreme Programming como alternativa para a construção de Objetos de Aprendizagem. In: 15o CIAED (Congresso Internacional ABED de Educação a Distância), Fortaleza, 2009.

NOBRE, Isaura A. M. et al. Informática na Educação: um caminho de possibilidades e desafios. Vitória: Editora Ifes, 2011.

VALENTE, José Armando. Diferentes Usos do Computador na Educação. 1993. Disponível em: http: //upf.tche.br/ carolina/pos/valente.html. Acesso em 10 mai 2014.

VIEIRA, Valter A. Consumerismo: Uma revisão nas áreas de influencia do comportamento do consumidor. In. Trabalho Acadêmico do Curso de Administração de Empresas e Comércio Exterior da Universidade Paranaense (UNIPAR) Campus Francisco Beltrão-Pr, 2004. 